\title{
A 79-year-old Woman with Acute Hepatitis B Caused by the Infection of Subgenotype D1 Hepatitis B Virus in Japan: A Case Study
}

\author{
Kosei Hashimoto ${ }^{1}$, Kouichi Miura ${ }^{1}$, Yoshinari Takaoka ${ }^{1}$, Hiroaki Nomoto ${ }^{1}$, Shunji Watanabe ${ }^{1}$, \\ Mamiko Tsukui ${ }^{1}$, Naoki Morimoto ${ }^{1}$, Norio Isoda ${ }^{1}$, Shigeo Nagashima ${ }^{2}$, Masaharu Takahashi ${ }^{2}$, \\ Hiroaki Okamoto ${ }^{2}$ and Hironori Yamamoto ${ }^{1}$
}

\begin{abstract}
:
A 79-year-old Japanese woman was diagnosed with acute hepatitis B based on laboratory tests showing positivity for IgM-class antibody against hepatitis B virus (HBV) core and hepatitis B surface antigen (HBsAg) as well as elevated transaminases. A phylogenetic analysis revealed that the HBV strain obtained from the patient belonged to genotype D/subgenotype D1, similar to strains circulating in foreign countries but different from those in Japan. The clinical course was favorable. HBsAg became negative within 10 weeks after the onset. To our knowledge, this is the first report of acute hepatitis B caused by subgenotype D 1 HBV in Japan.
\end{abstract}

Key words: acute hepatitis B, hepatitis B virus, subgenotype D1

(Intern Med 57: 3099-3104, 2018)

(DOI: 10.2169/internalmedicine.0977-18)

\section{Introduction}

Hepatitis B virus (HBV) infection causes acute hepatitis. $\mathrm{HBV}$ is transmitted by sexual intercourse, the use of HBVinfected medical devices or the transfusion of HBV-infected blood products. HBV infection can also become chronic, leading to liver cirrhosis and hepatocellular carcinoma (HCC). There are approximately 257 million and 1.2 million people with chronic HBV infection worldwide and in Japan, respectively (1). Because these patients represent potential sources of HBV infection, HBV infection remains a health burden worldwide.

There are at least $10 \mathrm{HBV}$ genotypes (A-J) that have distinct geographic distributions (2). For instance, genotypes B and $\mathrm{C}$ are predominantly distributed in South-Eastern Asia, including Japan. Genotype A is predominant in NorthWestern Europe and North America. In contrast, genotype D is distributed globally, including Europe, the Mediterranean region and West-Central Asia. A Japanese nationwide study showed that genotypes A, B, C and D accounted for $4.1 \%$, $17.5 \%, 77.6 \%$ and $0.6 \%$ of chronic HBV infections, respectively (3). Although native HBV genotypes are commonly observed as the cause of acute hepatitis B (4), the wave of globalization has changed the distribution of HBV genotypes in acute hepatitis B. At present, genotype A is the leading cause of acute hepatitis B in Japan, accounting for $46.7 \%$ of cases, followed by genotypes C (39.7\%) and B (11.8\%) (3). However, the prevalence of genotype D in Japan is still low in acute hepatitis $(0.18 \%)$ as well as in chronic HBV infection (0.6\%) (3).

In addition, HBV genotype $\mathrm{D}$ can be further divided into 10 subgenotypes (D1-D10) based on the nucleotide diversity over the entire genome (2). Of these subgenotypes, D2 is commonly observed in Ehime Prefecture in western Japan. HBV subgenotype D2 is believed to be a strain from Russia, as some asylums for Russian soldiers were located in Ehime during the Japanese-Russian War (1904-1905) (5). However,

${ }^{1}$ Division of Gastroenterology, Department of Medicine, Jichi Medical University School of Medicine, Japan and ${ }^{2}$ Division of Virology, Department of Infection and Immunity, Jichi Medical University School of Medicine, Japan

Received: February 7, 2018; Accepted: March 29, 2018; Advance Publication by J-STAGE: June 6, 2018

Correspondence to Dr. Kouichi Miura, miura385@jichi.ac.jp 
no other subgenotypes of genotype D have yet been reported in Japan.

We herein report a rare case of acute hepatitis $\mathrm{B}$ in an elderly woman caused by subgenotype D1 HBV.

\section{Case Report}

A 79-year-old Japanese woman was referred to our division due to abnormal liver function test results obtained in the division of Endocrinology and Metabolism of our hospital: $388 \mathrm{U} / \mathrm{L}$ for aspartate aminotransferase (AST) and 337 U/L for alanine aminotransferase (ALT). Regular blood tests as a follow-up for Graves' disease showed no abnormal liver function until two months before the admission. Because a follow-up examination revealed an elevation of transaminases (1,134 U/L for AST and $807 \mathrm{U} / \mathrm{L}$ for ALT), she was admitted to our hospital. She was an agriculture worker and had no history of alcohol intake, needle-stick injury, drug use or travel to foreign countries. Although she had been taking medication for Graves' disease from 2011, her thyroid function was within normal limits. The dosage of her medication for Graves' disease had not been changed. When she experienced subarachnoid hemorrhaging in 2011, a blood examination showed that her liver function was normal, and hepatitis B surface antigen (HBsAg) was negative. She had been receiving acupuncture care every week for chronic back pain since 2012. In addition, she had visited a nearby dental clinic for the treatment of caries four months before the admission. She had no family history of HBV infection.

On admission, there were no symptoms except for general fatigue. No skin lesions were observed. Laboratory tests were positive for $\mathrm{HBsAg}$, IgM-class antibody against $\mathrm{HBV}$ core (IgM-HBcAb) and HBV DNA (Table 1). Other viral infections, including those by hepatitis A virus, hepatitis $\mathrm{E}$ virus, hepatitis $\mathrm{C}$ virus, Epstein-Barr virus and cytomegalovirus, were absent, based on negative findings for acute markers of the corresponding viruses. Autoimmune hepatitis and primary biliary cholangitis were excluded by laboratory examinations. Although abdominal computed tomography (CT) showed a calculus in the gallbladder (Fig. 1), no findings of acute cholecystitis or cholangitis were observed. We therefore made a diagnosis of acute hepatitis B.

Fig. 2 shows the clinical course of the present case. No encephalopathy was observed during the hospital course. The serum AST and ALT levels decreased promptly and returned to normal at seven weeks after the initial presentation. The prothrombin time remained in the normal range after admission. HBsAg and HBV DNA became undetectable at 10 weeks and 3 months, respectively. After seven months, anti-HBs antibody became positive. No anti-HBV medication or prednisolone was used for treatment during the clinical course.

We identified the HBV genotype to be D, which is extremely rare in Japan, using an enzyme-linked immunosorbent assay (ELISA) (6). Thus, the full genomic sequence of the HBV strain (HB17-0791) recovered from the present patient was determined according to a previously described method (7) and deposited in the DDBJ/EMBL/GenBank databases under the accession number LC365689. A phylogenetic analysis confirmed that the HB17-0791 genome was classifiable as genotype D and further as subgenotype D1

Table 1. Laboratory Data on Admission.

\begin{tabular}{|c|c|c|c|c|c|c|}
\hline \multicolumn{2}{|c|}{ Peripheral Blood } & \multicolumn{2}{|c|}{ Biochemistry } & \multicolumn{3}{|l|}{ Serology } \\
\hline WBC & $4,500 / \mu \mathrm{L}$ & $\mathrm{TP}$ & $7.3 \mathrm{~g} / \mathrm{dL}$ & HBsAg & $>250 \mathrm{IU} / \mathrm{mL}$ & $(+)$ \\
\hline $\mathrm{RBC}$ & $390 \times 10^{4} / \mu \mathrm{L}$ & Alb & $3.7 \mathrm{~g} / \mathrm{dL}$ & $\mathrm{HBcAb}$ & $6.64 \mathrm{~S} / \mathrm{CO}$ & $(+)$ \\
\hline $\mathrm{Hb}$ & $12.6 \mathrm{~g} / \mathrm{dL}$ & BUN & $10.0 \mathrm{mg} / \mathrm{dL}$ & $\mathrm{HBeAg}$ & $481.71 \mathrm{~S} / \mathrm{CO}$ & $(+)$ \\
\hline $\mathrm{Ht}$ & $38.0 \%$ & $\mathrm{Cr}$ & $0.65 \mathrm{mg} / \mathrm{dL}$ & $\mathrm{HBeAb}$ & $0.00 \mathrm{INH} \%$ & $(-)$ \\
\hline \multirow[t]{2}{*}{ Plt } & $20.0 \times 10^{4} / \mu \mathrm{L}$ & T.Bil & $2.33 \mathrm{mg} / \mathrm{dL}$ & HBV DNA & 6.7 Log IU/mL & $(+)$ \\
\hline & & D.Bil & $1.18 \mathrm{mg} / \mathrm{dL}$ & $\mathrm{IgM}-\mathrm{HBcAb}$ & $21.0 \mathrm{~S} / \mathrm{CO}$ & $(+)$ \\
\hline \multicolumn{2}{|c|}{ Coagulation system } & AST & $1,134 \mathrm{U} / \mathrm{L}$ & IgA-HEVAb & $(-)$ & \\
\hline PT & $13.5 \mathrm{sec}$ & ALT & $804 \mathrm{U} / \mathrm{L}$ & IgM-HEVAb & $(-)$ & \\
\hline РT\% & $89.5 \%$ & LDH & $592 \mathrm{U} / \mathrm{L}$ & HCVAb & $(-)$ & \\
\hline \multirow[t]{6}{*}{ PT-INR } & 1.17 & ALP & $494 \mathrm{U} / \mathrm{L}$ & ANA & $40 x$ & $(+)$ \\
\hline & & $\gamma$-GTP & $104 \mathrm{U} / \mathrm{L}$ & AMA & $(-)$ & \\
\hline & & $\mathrm{ChE}$ & $179 \mathrm{U} / \mathrm{L}$ & ASMA & $(-)$ & \\
\hline & & & & $\operatorname{IgG}$ & $1,341 \mathrm{mg} / \mathrm{dL}$ & \\
\hline & & & & $\operatorname{Ig} \mathrm{A}$ & $442 \mathrm{mg} / \mathrm{dL}$ & \\
\hline & & & & $\operatorname{IgM}$ & $96 \mathrm{mg} / \mathrm{dL}$ & \\
\hline
\end{tabular}

RBC: red blood cell, Ht: hematocrit, Plt: platelet, PT: prothrombin time, INR: international normalized ratio,TP: total protein, Alb: albumin, BUN: blood urea nitrogen, Cr: creatinine, T.Bil: total bilirubin, D.Bil: direct bilirubin, AST: aspartate aminotransferase, ALT: alanine aminotransferase, LDH: lactate dehydrogenase, $\gamma$-GTP : $\gamma$-glutamyl transpeptidase, ChE: cholinesterase, HBsAg: hepatitis B surface antigen, HBcAb: anti-hepatitis B core antibody, HBeAg: hepatitis B e antigen, HBeAb: anti-hepatitis B e antibody, HEVAb: anti-hepatitis E virus antibody, HCVAb: anti-hepatitis C virus antibody, ANA: anti-nuclear antibody, AMA: anti-mitochondrial antibody, ASMA: anti-smooth muscle antibody 


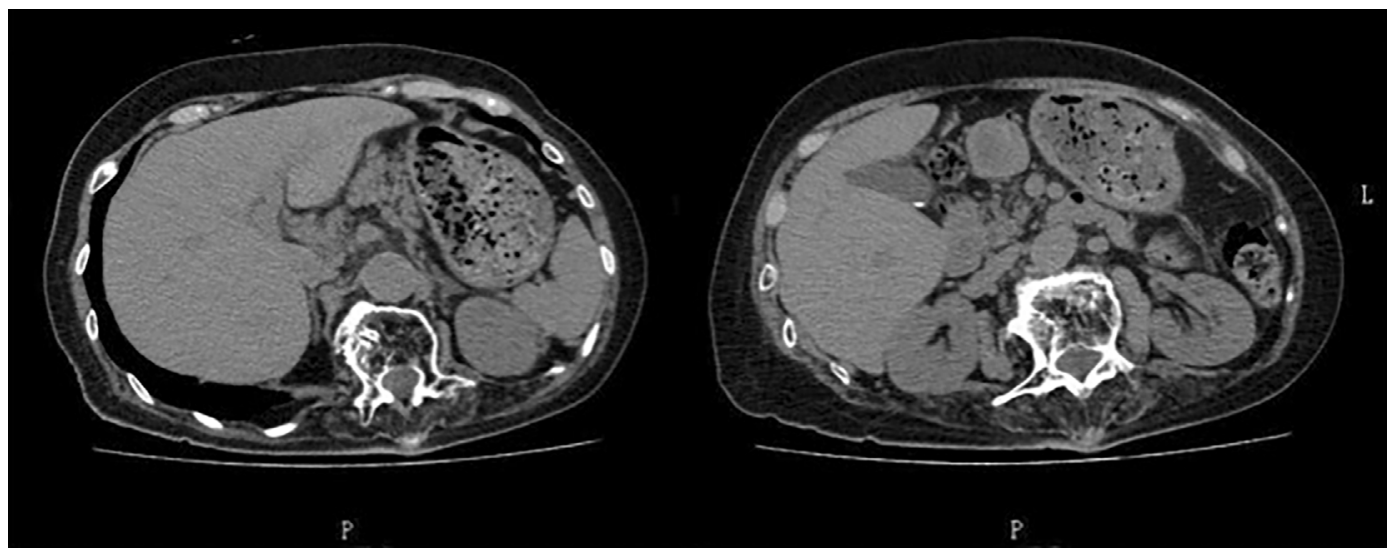

Figure 1. CT shows a small calculus in the gallbladder without gallbladder enlargement or common bile duct dilatation.

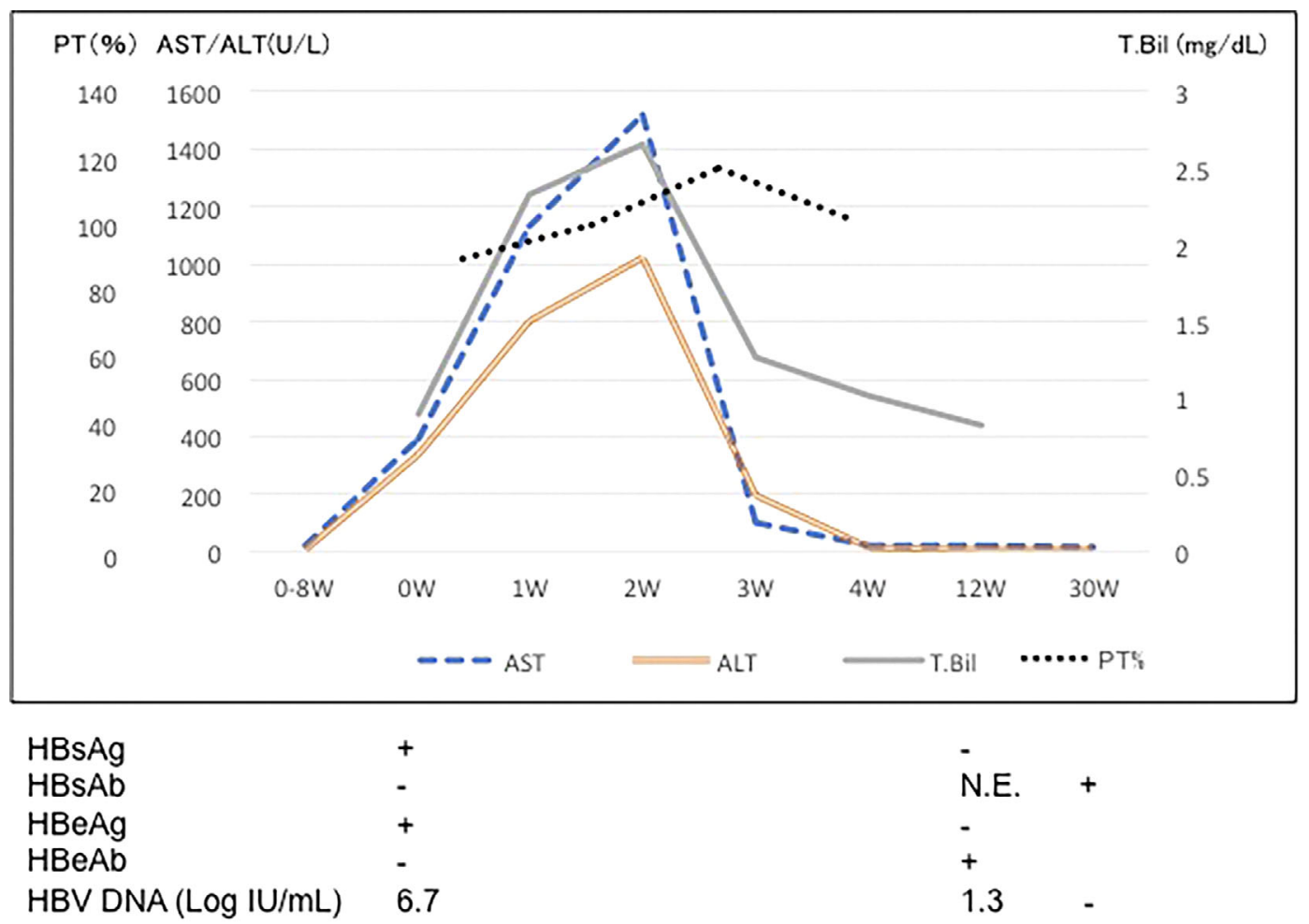

Figure 2. The clinical course of the present case. N.E.: not examined

(Fig. 3). Of note, the HB17-0791 strain was different from the HBV strains in Ehime Prefecture, where subgenotype D $2 \mathrm{HBV}$ strains were predominantly distributed. The HB170791 strain in the current case was rather close to those circulating in China, India, Tunisia and Vietnam (Fig. 3). There were no genetic mutations at the core promoter or pre-core regions of the HB17-0791 genome. Although the HBV strain was suspected of having been derived from foreign countries, we were unable to specify the origin of the HBV strain.

\section{Discussion}

We herein report an elderly patient with acute hepatitis B caused by a rare subgenotype (D1) of HBV. To our knowl- edge, this is the first report of a case of subgenotype D1 HBV infection in Japan.

In the present case, we made a diagnosis of acute hepatitis B based on the extremely high titer of IgM-HBcAb (21.0 $\mathrm{S} / \mathrm{CO}$ ). Unfortunately, the data of $\mathrm{HBcAb}$ before the onset of acute hepatitis were not available. However, the patient had no factors with the potential to reactivate HBV, including the use of immuno-suppressive agents and anti-cancer drugs. In addition, the patient was not under surgical stress or in a condition of compromised immunity, such as cancer, arteriosclerosis or diabetes, which can also reactivate HBV (8). We therefore considered the possibility of HBV reactivation to be extremely low.

We were concerned about the clinical course of the present case, as few data are available regarding acute hepatitis 


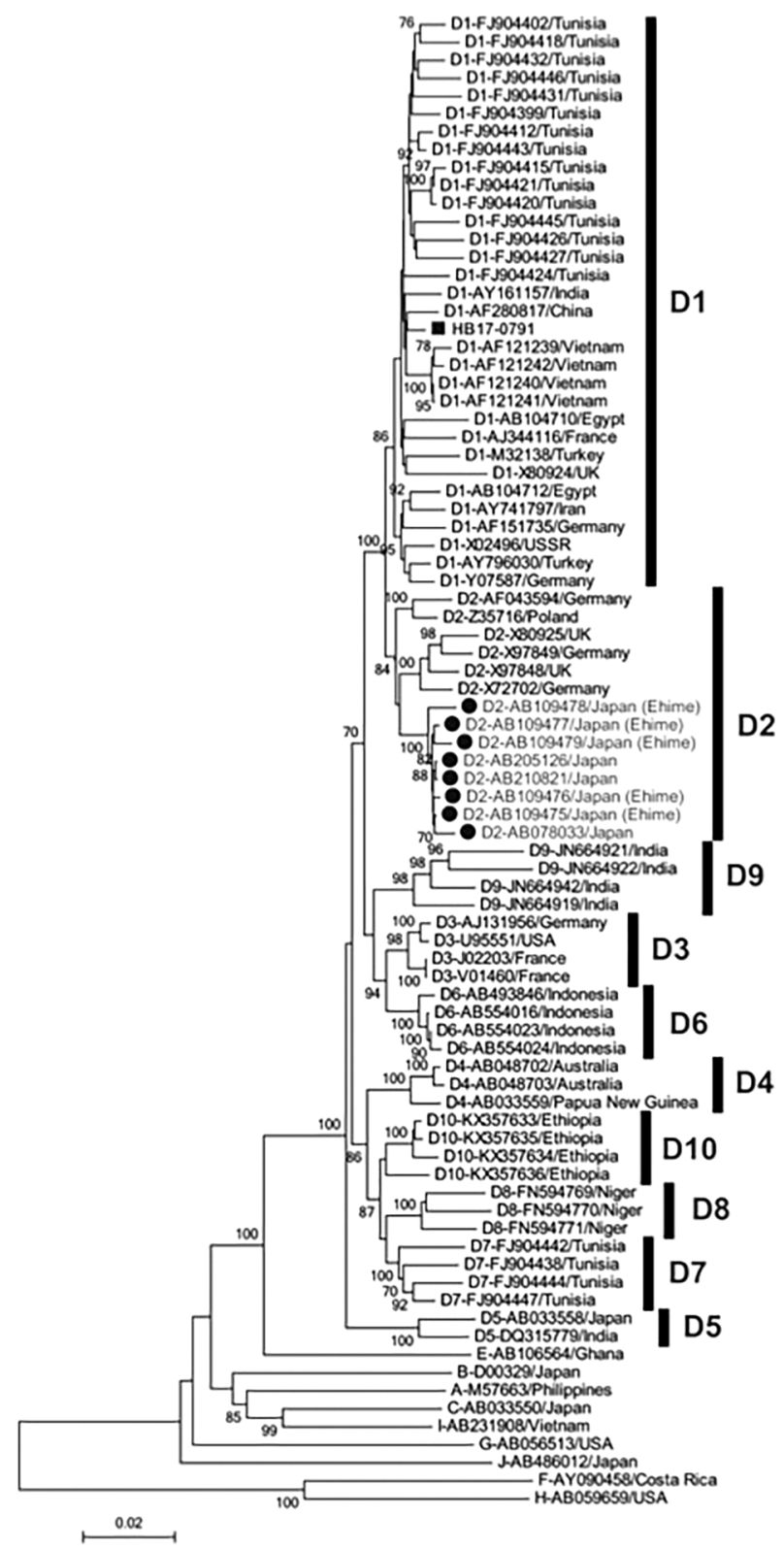

Figure 3. The phylogenetic tree constructed by the neighborjoining method based on the entire nucleotide sequences of $\mathrm{HBV}$ isolates of subgenotypes D1-D10 using the HBV strains of genotypes A-C and E-J as outgroups. In addition to the HBV strain (HB17-0791) whose entire genomic sequence was determined in the present study (indicated with a closed box), 73 representative HBV strains of subgenotypes D1-D10 were included for comparison. The reported strains are indicated with the genotype/subgenotype and accession no. followed by the country of isolation. The subgenotype D2 HBV strains isolated in Ehime, Japan, are highlighted by closed circles. Bootstrap values $(>\mathbf{7 0 \%})$ are indicated for the nodes as a percentage of the data obtained from 1000 resamplings. The scale bar is in units of nucleotide substitutions per site.

B caused by subgenotype D1 HBV. Fortunately, the patient recovered from acute hepatitis without any serious problems despite being given no specific medications for HBV infection. It has been reported that the clinical course of acute hepatitis B varies among genotypes. For instance, the peak

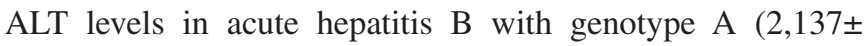
$1,088 \mathrm{U} / \mathrm{L})$ are significantly lower than those with genotypes B $(3,078 \pm 2,111 \mathrm{U} / \mathrm{L})$ or C $(2,624 \pm 1,843 \mathrm{U} / \mathrm{L})(3)$. In a study from India, the peak ALT value in acute hepatitis B caused by genotype D tended to be lower than that caused by genotype C (9). In contrast, the peak ALT level in Ehime Prefecture with genotype D was 2,236 $\pm 2,202 \mathrm{U} / \mathrm{L}$, which was higher than that with genotype A $(1,425 \pm 630 \mathrm{U} / \mathrm{L})(4)$. Although a weak immune response against HBV may lead to a delay in the disappearance of $\mathrm{HBsAg}$, as in the cases with genotype A HBV, HBsAg became negative within 10 weeks after the disease onset in the present case. The chronicity of HBV genotype D is of interest; however, accurate data have not yet been published. In general, the chronicity of HBV genotype D is suspected to be low $(10,11)$. Although the rate of fulminant hepatitis followed by acute hepatitis was unclear, HBV genotype D has been reported as a cause of fulminant hepatitis in Japan (12) as well as in foreign countries $(13,14)$. Among cases with genotype D $\mathrm{HBV}$, no significant differences were observed in the peak levels of ALT or total bilirubin between subgenotypes D1 and D2 (9). However, little information is available on the clinical course of patients with acute HBV subgenotype D1 infection.

In patients with chronic hepatitis B caused by subgenotype D2 HBV observed in Ehime Prefecture, the prevalence of liver cirrhosis and HCC was less common than in cases caused by genotype C (15). In Turkey, subgenotype D1 $\mathrm{HBV}$ is the major cause of chronic hepatitis $\mathrm{B}$, being characterized by early $\mathrm{HBeAg}$ seroconversion, a low viral load and a relatively low incidence of liver cirrhosis and HCC (16). Thus, HBV genotype D seems to be associated with a less severe clinical course in cases of acute and chronic hepatitis.

The transmission route is a major concern in the present case. Horizontal transmission is the major mode in genotype D (10). Sexual transmission is the leading cause of acute hepatitis B in Japan (3). However, the patient denied sexual intercourse by a medical interview. In addition, she had no family history of $\mathrm{HBV}$ infection. We therefore suspected two potential routes of transmission: acupuncture care and dental treatment, both of which carry a risk of HBV transmission $(17,18)$. The phylogenetic tree showed that the HBV strain in the present case was different from those in Ehime, Japan, instead being segregated into a cluster including strains isolated in China, India and Vietnam. As the patients had never been to theses foreign counties, we suspected that the isolated strain may have been transported from those countries via infected individuals because the distribution of genotype D HBV is extremely low in Japan, and the number of foreign residents is increasing in Tochigi Prefecture, where the patient lives (accounting for $1.82 \%$ of the population; http://www.pref.tochigi.lg.jp/f04/29-gaikokuji njumin.html). The top five countries of origin among foreign residents of Tochigi Prefecture are China, the Philippines, 
Table 2. The Prevalence of Chronic HBV Infection and HBV Genotypes.

\begin{tabular}{lccc}
\hline & $\begin{array}{c}\text { Frequency of } \\
\text { HBs antigen }\end{array}$ & Major genotype & Subgenotype D1/D \\
\hline China & $5.49 \%$ & $\mathrm{C}>\mathrm{B}>\mathrm{D}(1.16 \%)^{20)}$ & $\left.53 / 60(88.3 \%)^{25) 26}\right)$ \\
Philippines & $4.63 \%$ & $\mathrm{~A}>\mathrm{C}>\mathrm{B}(\mathrm{D} \text { was not found })^{23)}$ & \\
Brazil & $0.65 \%$ & $\mathrm{~A}>\mathrm{D}(23.4 \%)>\mathrm{F}^{21)}$ & $0 / 80(0 \%)^{30)}$ \\
Vietnam & $10.80 \%$ & $\mathrm{~B}>\mathrm{C}>\mathrm{D}(5.2 \%)^{22)}$ & \\
Peru & $2.10 \%$ & $\mathrm{~F}$ only 24$)$ & $0 / 20(0 \%)^{5)}$ \\
Japan & $1.02 \%$ & $\mathrm{C}>\mathrm{B}>\mathrm{A}>\mathrm{D}(0.6 \%)^{3)}$ & \\
\hline
\end{tabular}

Brazil, Vietnam and Peru. Furthermore, the prevalence of people with HBsAg is higher in these Asian countries and Peru than in Japan (19). In the literature, HBV genotype D is prevalent in China (20), Brazil (21), and Vietnam (22) but not in the Philippines (23) or Peru (24) (Table 2). Furthermore, subgenotype D1 is observed in China $(25,26)$. Thus, there is a chance of becoming infected with subgenotype D1 HBV in Japan. Because HBV carriers are often unaware of their HBV infection, HBV may be unknowingly transmitted from infected foreigners to susceptible residents in Japan. It is important to bear in mind that acupuncture and dental procedures carry a risk of HBV infection, and safe working environments must be established in order to prevent $\mathrm{HBV}$ infection.

In conclusion, we experienced a case of acute hepatitis B caused by an infection with subgenotype D1 HBV, which was identified for the first time in Japan. Further investigations are required, as HBV infection with non-native genotypes is likely to become increasingly frequent in Japan due to growing globalization (3, 27-29).

The authors state that they have no Conflict of Interest (COI).

\section{References}

1. Tanaka J, Akita T, Ohisa M, et al. Trends in the total numbers of HBV and HCV carriers in Japan from 2000 to 2011. J Viral Hepatol 1-10, 2017.

2. Ozaras R, Balkan II, Yemisen M, Tabal F. Epidemiology of HBV subgenotypes D. Clin Res Hepatol Gastroenterol 39: 28-37, 2015.

3. Ito $\mathrm{K}$, Yotsuyanagi $\mathrm{H}$, Sugiyama $\mathrm{M}$, et al. Geographic distribution and characteristics of genotype A hepatitis B virus infection in acute and chronic hepatitis B patients in Japan. J Gastroenterol Hepatol 31: 180-189, 2016.

4. Matsuura K, Michitaka K, Yamauchi K, et al. Characteristics of geographic distributions and route of infection for hepatitis B virus genotype D in Ehime area in western Japan. Hepatol Res 37: 255262, 2007.

5. Michitaka K, Tanaka Y, Horiike N, et al. Tracing the history of hepatitis B virus genotype D in western Japan. J Med Virol 78: 44-52, 2006.

6. Usuda S, Okamoto $H$, Iwanari $H$, et al. Serological detection of hepatitis B virus genotypes by ELISA with monoclonal antibodies to type-specific epitopes in the preS2-region product. J Virol Methods 80: 97-112, 1999.

7. Mulyanto, Pancawardani P, Depamede SN, et al. Identification of four novel subgenotypes (C13-C16) and two inter-genotypic recombinants $(\mathrm{C} 12 / \mathrm{G}$ and $\mathrm{C} 13 / \mathrm{B} 3)$ of hepatitis B virus in Papua
Province, Indonesia. Virus Res 163: 129-140, 2012.

8. Kamitsukasa H, Iri M, Tanaka A, et al. Spontaneous reactivation of hepatitis B virus (HBV) infection in patients with resolved or occult HBV infection. J Med Virol 87: 589-600, 2015.

9. Sarkar N, Pal A, Das D, et al. Virological characteristics of acute hepatitis B in eastern India: critical differences with chronic infection. PLoS One 10: 1-15, 2015.

10. Liu C-J, Kao J-H. Global perspective on the natural history of chronic hepatitis B: role of hepatitis B virus genotypes A to J. Semin Liver Dis 33: 97-102, 2013.

11. Ito $\mathrm{K}$, Yotsuyanagi $\mathrm{H}$, Yatsuhashi $\mathrm{H}$, et al. Risk factors for longterm persistence of serum hepatitis B surface antigen following acute hepatitis B virus infection in Japanese adults. Hepatology 59: 89-97, 2014.

12. Ozasa A, Tanaka Y, Onto E, et al. Influence of genotypes and precore mutations on fulminant or chronic outcome of acute hepatitis B virus infection. Hepatology 44: 326-334, 2006.

13. Leblebicioglu H, Eroglu C. Acute hepatitis B virus infection in Turkey: epidemiology and genotype distribution. Clin Microbiol Infect 10: 537-541, 2004.

14. Arankalle VA, Gandhi S, Lole KS, Chadha MS, Gupte GM, Lokhande MU. An outbreak of hepatitis B with high mortality in India: association with precore, basal core promoter mutants and improperly sterilized syringes. J Viral Hepat 18: 20-28, 2011.

15. Duong TN, Horiike N, Michitaka K, et al. Comparison of genotypes $\mathrm{C}$ and $\mathrm{D}$ of the hepatitis $\mathrm{B}$ virus in Japan: a clinical and molecular biological study. J Med Virol 72: 551-557, 2004.

16. Sunbul M, Sugiyama M, Kurbanov F, et al. Specific mutations of basal core promoter are associated with chronic liver disease in hepatitis B virus subgenotype D1 prevalent in Turkey. Microbiol Immunol 57: 122-129, 2013.

17. Zhong L, Xi G, Zhang L, et al. The estimation of prevalence and risk factors of hepatitis B virus infection among blood donors in Chengdu, China. J Med Virol 88: 260-267, 2016.

18. Radcliffe RA, Bixler D, Moorman A, et al. Hepatitis B virus transmissions associated with a portable dental clinic, West Virginia, 2009. J Am Dent Assoc 144: 1110-1118, 2013.

19. Schweitzer A, Horn J, Mikolajczyk RT, Krause G, Ott JJ. Estimations of worldwide prevalence of chronic hepatitis B virus infection: a systematic review of data published between 1965 and 2013. Lancet 386: 1546-1555, 2015.

20. Zhu CT, Dong CL. Characteristics of general distribution of hepatitis B virus genotypes in China. Hepatobiliary Pancreat Dis Int 8 : 397-401, 2009.

21. Lampe E, Mello FCA, do Espírito-Santo MP, et al. Nationwide overview of the distribution of hepatitis B virus genotypes in Brazil: a 1000-sample multicentre study. J Gen Virol 98: 1389-1398, 2017.

22. Do SH, Yamada H, Fujimoto M, et al. High prevalences of hepatitis $\mathrm{B}$ and $\mathrm{C}$ virus infections among adults living in Binh Thuan province, Vietnam. Hepatol Res 45: 259-268, 2015.

23. Sakamoto T, Tanaka Y, Orito E, et al. Novel subtypes (subgenotypes) of hepatitis B virus genotypes $\mathrm{B}$ and $\mathrm{C}$ among chronic liver 
disease patients in the Philippines. J Gen Virol 87: 1873-1882, 2006.

24. Casey JL, Niro GA, Engle RE, et al. Hepatitis B virus (HBV) hepatitis $\mathrm{D}(\mathrm{HDV})$ coinfection in outbreaks of acute hepatitis in the Peruvian Amazon basic: the roles of HDV genotypes III and HBV genotype F. J Infect Dis 174: 920-926, 1996.

25. Yin J, Zhang H, He Y, et al. Distribution and hepatocellular carcinoma-related viral properties of hepatitis B virus genotypes in Mainland China: A community-based study. Cancer Epidemiol Biomarkers Prev 19: 777-786, 2010.

26. Nie J, Li J, Sun K, et al. HBV/D1: a major HBV subgenotype circulating in Uyghur patients with chronic HBV infection in Xinjiang, China. Arch Virol 157: 1541-1549, 2012.

27. Kobayashi M, Suzuki F, Arase Y, et al. Infection with hepatitis B virus genotype A in Tokyo, Japan during 1976 through 2001. J Gastroenterol 39: 844-850, 2004.
28. Matsuura K, Tanaka Y, Hige S, et al. Distribution of hepatitis B virus genotypes among patients with chronic infection in Japan shifting toward an increase of genotype A. J Clin Microbiol 47: 1476-1483, 2009.

29. Orito E, Ichida T, Sakugawa H, et al. Geographic distribution of hepatitis B virus (HBV) genotype in patients with chronic HBV infection in Japan. Hepatology 34: 590-594, 2001.

30. Roman S, Jose-Abrego A, Fierro NA, et al. Hepatitis B virus infection in Latin America: a genomic medicine approach. World $\mathrm{J}$ Gastroenterol 20: 7181-7196, 2014.

The Internal Medicine is an Open Access journal distributed under the Creative Commons Attribution-NonCommercial-NoDerivatives 4.0 International License. To view the details of this license, please visit (https://creativecommons.org/licenses/ by-nc-nd/4.0/).

(C) 2018 The Japanese Society of Internal Medicine Intern Med 57: 3099-3104, 2018 